\title{
PSICOESFERA: USO CORPORATIVO DA ESFERA TÉCNICA DO TERRITÓRIO E O NOVO ESPÍRITO DO CAPITALISMO
}

\section{Psychoesphere: corporate use of territory's technical sphere and the new spirit of capitalism}

\author{
Samira Peduti Kahil \\ Professora dos cursos de Graduação e Pós-Graduação em Geografia, \\ ICGE, UNESP, Campus Rio Claro \\ Rio Claro/SP - Brasil \\ jckc@uol.com.br
}

Artigo recebido para publicação em 16/12/2010 e aceito para publicação em 27/12/2010

RESUMO: Durante algum tempo acreditou-se que as grandes transformações no meio técnico-cientifico informacional levariam, necessariamente, à renovação das sociabilidades. Mas, o que dizer quando nenhum acontecimento, nenhum evento é capaz de romper a estabilidade dos padrões éticos normativos dos sistemas de ações hegemônicos de nossas sociedades capitalistas? Este artigo visa compreender tal fenômeno, retomando de maneira sistemática a idéia de psicoesfera e tecnoesfera. Para tanto, procura analisar a indissociabilidade dos sistemas técnicos e dos sistemas de ações; indissociabilidade fundada numa racionalidade técnico-cientifica capaz de constituir valores e critérios normativos de justificação e estabilização nas sociedades capitalistas, mesmo em um meio geográfico em que é aparente a desagregação e decomposição das sociabilidades, precedida pelo aprofundamento das desigualdades territoriais.

Palavras-chave: Psicoesfera. Tecnoesfera. Racionalidade técnico-científica. Uso do território.

ABSTRACT: For some time it was believed that the great transformations in the technical-scientific-information system would lead, necessarily, to the renewal of sociabilities. But what to say when neither an incident nor an event is capable of breaking up the stability of the normative ethical models from the hegemonic action systems of our capitalist societies? This article aims to understand such phenomenon, systematically retrieving the psychosphere and technosphere idea. For so, it seeks to analyze the inseparability of technical systems and systems of actions; inseparability established in a techno-scientific rationality capable of building values and normative standards of justification and stabilization in the capitalist societies, even in a geographical environment where it is evident the sociability's dissolution and disintegration, preceded by the deepening of territorial inequalities.

Keywords: Psychosphere. Technosphere. Techno-scientific rationality. Use of territory. 


\section{INTRODUÇÃO: UM RECLAMO E ALGUMAS PREMISSAS PARA DESARMAR O RACIOCÍ- NIO}

Insistentemente temos reclamado esclarecimento conceitual aos trabalhos acadêmicos; temos insistentemente convocado nossos alunos e colegas pesquisadores a recusar lealdade às convenções lingüísticas e conceituais em vigor; convenções estas, muito responsáveis eu diria, pela falência da crítica e pelo estado atual de depravação da linguagem, ou seja, momento em que o "pensamento se converteu em mercadoria e a linguagem em seu encarecimento" (ADORNO; HORKHEIMER, 1985, p.12).

Nossa época, cheia de paradoxos, de dificil visibilidade e de definições complexas desafiam nossa capacidade de entendimento e conceitualização. Durante séculos caminhamos do desconhecido ao conhecido; e agora fazemos a viagem em sentido inverso, do conhecido ao desconhecido: nada nos escapa e, no entanto tudo nos escapa. A histórica oposição entre o conhecido e o desconhecido, entre a essência e aparência, entre o ideológico e o real, é hoje uma oposição entre o Mundo e suas imagens que podem ser fabricadas e impostas como se elas fossem o Mundo (SANTOS, 1995, $p$. 1077 - tradução nossa).

Por muito tempo, a interpretação dos fenômenos foi realizada sob a ótica do conhecimento auferido da realidade que se apresenta no mundo exterior. Mas hoje, quando parece ninguém duvidar do aspecto subliminar da psique humana, do fetiche de todo desejo humano criado na tensão entre o inconsciente e o consciente, investigados por Sigmund Freud (1856-1939), ou antes, prenunciada por Karl Marx (1818-1883) no capítulo de "O Capital" sobre o fetiche da mercadoria, onde estabelece o conceito de alienação como a produção "inconsciente" de mais-valia expropriada do trabalhador, ou ainda quando, sob a perspectiva filosófica do princípio da complementaridade de Neils Bohr (1885-1962), advoga-se existir um elemento arbitrário implícito no conceito de observação - não seria necessário recorrer aos clássicos para defender o tácito poder do pensamento crítico-reflexivo e o caráter político da ciência.

Mas, hoje, a despeito de todo conhecimento alcançado pela humanidade, a despeito de todo esclarecimento quanto à imanência política da razão científica e a despeito do "princípio de que a liberdade na sociedade é inseparável do pensamento esclarecedor", nos dizem Adorno e Horkheimer, o pensamento encontra-se paralisado pelo "medo de afastar-se dos fatos - fatos esses que, no entanto, já estão pré-moldados como clichês na própria percepção pelas usanças dominantes na ciência, nos negócios e na política". "Ao tachar de compilação obscura e, de preferência, de alienígena o pensamento que se aplica negativamente aos fatos, bem como às formas de pensar dominantes, e ao colocar assim um tabu sobre ele, esse conceito [de esclarecimento, ou seja, de obscurecimento] mantém o espírito sob o domínio da mais profunda cegueira." (ADORNO; HORKHEIMER, 1985, p.13).

Portanto, o que reclamamos ao debate acadêmico é a introdução de um mínimo de negatividade da certeza cientificista dos fatos, buscando revelar o que há de frágil tanto na segurança perlocucionária dos conceitos das quais se serve a ciência, quanto na análise crítica das formas históricas concretas que estão em sua base mais funda.

É com este espírito que temos buscado encaminhar nossas pesquisas e interpretações do espaço geográfico e das dinâmicas do território brasileiro. O desafio maior do tema proposto para este ensaio é exemplar dessa propensão em tratar com o indemonstrável e que requer uma forçagem do pensamento, procedimento praticamente interdito na produção científica de nosso tempo. Sob um nominalismo intransigente, ou sob o persistente cientificismo empiricista, a simples referência ao conceito "psicoesfera" como modo de vida ou espírito de época, parece feiticismo, ou fetichismo conceitual. De acordo com as regras do método científico só poderíamos descrever e classificar os modos de comportamento social, como o behaviorismo de fato planejava, a partir das reações particulares consolidadas e passíveis de serem traduzidas, nomeadas como formas de ações objetivadas (no mais das vezes tratadas através de indexações, classificações, ponderações sondagens, etc). 
Prendendo o assunto numa trama fina podemos agora dizer que não temos como definir "psicoesfera", nem teórica nem praticamente, isolando ou individualizando algum elemento metafisicamente derradeiro e imutável da esfera sócio-espacial. Portanto, considerando a natureza do "espaço geográfico como um conjunto de sistemas de objetos indissociável dos sistemas de ações" e tomando o conceito de território como dimensão política do espaço geográfico poderíamos definir "psicoesfera" muito mais como um fator em um duplo sentido: ela não é isolável e acha-se entretecida à esfera técnica do território e, portanto, a um momento nodal histórico e, sem nenhum romantismo de nossa parte, poderíamos dizer, - é o espírito de uma época (Zeitgeist). "Psicoesfera" é paráfrase virtuosa de Milton Santos para o conjunto de crenças, desejos, hábitos, linguagem, sistemas de trabalho, associados ao espírito de uma época. (SANTOS, 1988b, p.313).

Sabemos como, em Milton Santos, psicoesfera e tecnoesfera são complementares e, por suposto, a esfera técnica, mesmo como sistema de objetos técnicos, não poderia ter valor ou significado em si. Os objetos (naturais ou artificiais) têm realidade per se ou autonomia de existência, devida à sua constituição material ou sua realidade corpórea, mas não têm autonomia de significação, não fosse sua existência relacional (quer consideremos relações entre coisas, ou seja, sistema de objetos, quer consideremos a relação entre sujeito-objeto).

Da premissa, portanto, de que o espaço geográfico é um conjunto de sistemas de ações indissociável dos sistemas de objetos, podemos proceder à análise do espírito de nossa época, sem ceder à cisão vulgar entre essência e aparência, entre o real e o imaginado, entre o individual e universal, entre objetos e ações, entre sociedade e natureza, entre o lugar e o mundo. O que também nos permite entender que o real não é a teoria, mas o reconhecimento do real da experiência de que falam os conceitos que construímos e que servem para levantar questões sobre o real, refazendo os passos do pensamento que conceituou a coisa da experiência. Podemos dizer, tal teoria é muito mais uma posição filosófica, nos oferece a possibilidade de questionar, de exercitar o pensamento a conhecer a realidade, por si próprio. $\mathrm{O}$ que favoravelmente nos possibilita a construção de um pensamento imanente à natureza do espaço, uma epistemologia "como algo situado entre a teoria e o real: você constrói a teoria e ela própria lhe permite extrair uma epistemologia, isto é, o acesso ao real. E esta teoria também já veio do real por outro caminho, que é histórico, que é este mundo novo que está se fazendo". (SANTOS, 1994, p. 174).

Neste ponto, na confluência do que está nos embaraçando desde o início, podemos avançar no enunciado com a questão: o que é o mundo, qual espírito de nossa época?

$\mathrm{Na}$ fase atual da história, mais que nunca, o Mundo é uma trama complexa de acontecimentos entretecidos por uma profusão de eventos e uma também complexa vida de relações. Mas o que é o Mundo senão um conjunto de possibilidades do acontecer? Ou seja, o "mundo se dá como latência, um conjunto de possibilidades até que, chamadas a se realizar, transformam-se em extenso." Tais possibilidades reais, histórica e geograficamente irrealizadas, se tornam realizadas através da ação, dos eventos que acontecem, se realizam nos lugares como particularidades imanentes do mundo. O lugar se define assim como particularidade imanente ao mundo - um movimento interativo no qual mundo e lugar fertilizam-se mutuamente (SANTOS, 1996, p. 99). É bom ter em conta que o lugar não é uma parte do Mundo. O lugar é o Mundo em movimento - um movimento dinamizado pelos eventos - um movimento permanente de metamorfose do real-abstrato em real-concreto, e vice-versa - dito de outra maneira, a totalidade em perpétuo movimento. E são, pois, os eventos que unem em movimento interativo o mundo e o lugar, universalidade e particularidade, e que, empiricizando o mundo nos lugares transformam o todo, que é uma integral, em seus diferenciais.

Nesta nova fase da história, o espaço geográfico é um dos mais importantes aspectos das compossibilidades de realização do Mundo - dado o estágio técnico-científico e informacional contemporâneo possibilitar indissociavelmente sistemas de ações e sistemas de objetos alcançarem lugares no mundo. Ao alcançar os lugares, o Mundo muda ao mesmo tempo em que uma nova dinâmica se instala no lugar. Assim os lugares se diferenciam pelo fato de que são diversamente alcançados, seja qualitativa, seja quantitativamente, pelos sistemas de ações e sistemas de objetos. 
Em nossa época, a "universalização do mundo pode ser constatada nos fatos" (SANTOS, 1988a, p.14). O próprio espaço geográfico é evidência do Mundo - ele é forma e conteúdo das evidências dos diversos momentos do processo de mundialização: multinacionalização das firmas e a internacionalização da produção e do produto; universalização das trocas, universalização do crédito, universalização do consumo, universalização da informação, etc., portanto, podemos afirmar que a totalidade, a universalidade não é mais uma criação de nosso pensamento - não é mais uma abstração, não é somente uma idéia ou ideal da modernidade. $\mathrm{E}$, isto tudo não quer dizer que o mundo se tornou homogêneo e as diferenças sociais ou espaciais se apagaram. Bem o contrário, o que é evidente é um aprofundamento das desigualdades, universalização da pobreza, das doenças, da ignorância, etc... que não podem ser explicadas sem levarmos em conta as evidências da universalização das hegemonias, das oligarquias, de uma racionalidade instrumental ao capital que universaliza uma cultura que ameaça o homem de uma também alienação total.

\section{O USO CORPORATIVO DA ESFERA TÉCNICA DO TERRITÓRIO E O NOVO ESPÍRITO DO CAPITALISMO}

De fato, a configuração do território, a materialidade do espaço, os sistemas de objetos (naturais e artificiais) têm existência própria, já o dissemos, mas é o espaço geográfico, um híbrido de sistemas de ações e sistemas de objetos, que em conjunto redefine os objetos mudando seu significado; mas, os objetos técnicos são artifícios criados pelo homem e, portanto, intencionalidade, racionalidade, significado the é intrínseco. Assim, "os objetos técnicos tendem a ser ao mesmo tempo técnicos e informacionais, já que, graças à extrema intencionalidade de sua produção e de sua localização, eles já surgem como informação"; (...) e, "a informação não apenas está presente nas coisas, nos objetos técnicos, que formam o espaço, como ela é necessária à ação realizada sobre essas coisas" (SANTOS, 1996, p.190-191).

Entendendo por sistemas técnicos o conjunto das técnicas que, a cada momento, vem constituir a base material da vida das sociedades e representativos da forma como em cada época uma sociedade compartilha o espaço, os sistemas técnicos sucessivos permitem-nos o entendimento das diversas formas históricas de estruturação, funcionamento e articulação dos territórios.

No processo histórico de desenvolvimento das forças produtivas, principalmente após a segunda guerra mundial, assistimos uma profunda interação entre a ciência e a técnica - união promovida sob o comando e financiamento do capital. E hoje, nos encontramos no momento auge dessa tragédia que transformou a razão esclarecedora em razão instrumental e que marcaria profundamente o espírito de nossa época; momento em que a ciência, a cultura e a política, dominadas por uma técnica marcadamente informacional e instrumental ao capital e ao serviço das corporações e instituições multinacionais, administram o ritmo de nossas vidas e a dinâmica dos territórios. É assim que, ao mesmo ritmo e também sob a égide do mercado, o meio geográfico, agora um meio técnico-científico e informacional se organiza para atender, sobretudo aos interesses dos agentes hegemônicos da economia, da cultura e da política.

Neste ponto, podemos então afirmar que em nossa época o espírito do capitalismo se universaliza como modo de racionalização do espaço geográfico. E, nesse sentido falar em uso corporativo do território é a categoria adequada para expor a normatividade interna da forma hegemônica de ordenamento dos sistemas de objetos e de justificação da conduta das ações (corporativas), ou seja, forma hegemônica de compartilhar o espaço no capitalismo contemporâneo. Falamos aqui em hegemonia admitindo que tal racionalidade, mesmo não sendo a única, tem a força de determinar a tendência de todas as demais formas de desenvolvimento do processo de produção material da vida na fase atual do capitalismo.

Sabemos como, em Max Weber, o espírito do capitalismo é justamente este conjunto de crenças associadas à ordem capitalista que contribui para justificar esta ordem e a sustentá-la, legitimando os modos de ação e as disposições que são coerentes com ela. No entanto, podemos dizer que cada fase do capitalismo exige um éthos específico e que hoje o consumo tornase o grande fundamentalismo da sociedade. 
Que em nosso momento histórico a mercadoria torna-se o laço social organizador da sociedade é algo que certos diagnósticos de época não cessam de repetir e certamente, precisam o caráter contraditório do modo de organização do capitalismo - caráter contraditório, já anunciado pelo jovem Karl Marx dos "Manuscritos" (1844). Mas, hoje quando exatamente o caráter contraditório da organização das formas de vida no capitalismo contemporâneo se ajusta e se torna adequado ao regime de super-acumulação, podemos dizer que estamos diante de uma estrutura contraditória paradoxal. "Entendendo-se por 'estrutura' uma identidade complexa constituída por uma pluralidade de momentos" (LACLAU, 1996, p. 28) e, o que no limite nos ajuda entender o paradoxo para além da contradição é a identificação das situações de regime de contradição; regime de certa forma, realizado e legitimado nas formas de organização sócio-espaciais sob os imperativos do capitalismo contemporâneo. É esse processo de institucionalização das contradições, legitimadas ou não, que desfazem qualquer potencialidade da crítica das contradições. (SSAFATLE, 2008; BOLTANSKI; CHIAPELLO, 1999). "Vivemos hoje, um mundo do paradoxo em estado puro" nos diz Milton Santos, em entrevista a Silvio Tendler, em 04/01/2001. "Nunca houve uma fase da história do homem na qual tudo fosse paradoxal. Então, ou a gente parte do paradoxo como uma vizinhança normal do cotidiano, ou a gente não se prepara para entender o que nos rodeia".

Dizíamos, a razão pragmática e instrumental às finalidades do capital que orienta a criação e o ordenamento dos sistemas de objetos é a mesma que justifica a conduta das ações na contemporaneidade. Aliás, é muito comum hoje, a razão científica justificar a conduta das ações, já que o próprio conteúdo de informação técnica e científica é que parece possibilitar ações mais precisas e resultados mais eficazes. Mas isto não é tudo. A informação técnico-científica é que permite a coordenação das ações, indicando o momento e o lugar da realização das atividades. E, é assim, presididas por uma razão formalizada, segundo o mesmo código ou mesmo dogma, que as ações se dão em sistemas. Tais sistemas de "ações formalizadas" num sistema performativo de "palavras que se presumem projetos para ação" (HORKHEIMER,
1976, p.101), cuja repetição acaba por tornar-se base aparentemente sólida da interpretação científica e da própria justificação das ações, são o núcleo motor da máquina ideológica feita de peças que se alimentam mutuamente e põem em movimento os elementos essenciais do novo espírito do capitalismo.

Vem daqui, mais uma vez, nosso reclamo de que é preciso recusar lealdade às convenções lingüísticas e conceituais em vigor nesta nossa época. "Nesta época, de razão formalizada, as doutrinas se sucedem tão rapidamente que cada uma delas é considerada apenas como outra ideologia" (idem ibidem), embora cada uma se torne uma razão temporária de justificação e legitimação das ações hegemônicas. Devemos isto sim, procurar atualizar o pensamento, não deixar o pensamento subsumir-se a um vocábulo único, uma racionalidade única, nem deixar que se feche em uma ontologia, uma analítica ou em uma doutrina. O tempo do pensamento está aberto para um regime de apreensão diferente. Um pensamento que não se satisfaça, por exemplo, com o que considero antiga definição de ideologia, ou seja, a idéia de que a ideologia é a ilusão que preenche a lacuna da impossibilidade do pensamento encontrar o real (concreto). A ilusão é que, superando o vazio a priori, chega-se à coisa real. Esta é uma visão padronizada que, grosso modo, teríamos que inverter, considerando, instigados aqui por Slavoj Zizek (2004) e Ernesto Laclau (1978), que a ideologia também funciona como forma de regular uma certa distância com o encontro, sustentando exatamente aquilo que quer evitar no nível da realidade. Não seria o caso das causas humanitárias de certa forma um modo de evitar encontrar o real, evitar o encontro com o outro, manter distância conveniente com o horror do real? Fundamentada no ardente desejo que as pessoas têm de se adaptar a alguma coisa que tenha o poder de se instituir, as causas humanitárias, não são somente expressão de amor ao próximo, são exatamente o oposto. A função do dinheiro, nas doações para causas humanitárias, significa que eu pago a você para que "fique longe de mim". Não seria esse o mesmo caso de pagar a prostituta para fazer sexo, convenientemente sem envolvimento?

E não seria o mesmo caso da instituição performativa da idéia de globalização que nos faz crer que a difusão instantânea da informação realmente informa 
as pessoas ou, nos faz crer que o mercado é capaz de ser tolerante, respeitar as diferenças e ser democrático, enquanto o imperativo, o culto ao consumo é estimulado? E não seria o caso da força perlocucionária que têm os discursos sobre o fim das fronteiras, da liberdade sem limites ou do fim do Estado, quando o que estamos vendo é seu fortalecimento para atender aos reclamos das corporações e instituições internacionais, em detrimento dos cuidados com as populações cuja vida se torna mais difícil?

Portanto, podemos agora dar um passo adiante buscando descrever, mesmo que a título de exemplo, como a estrutura paradoxal da racionalidade hegemônica é atualmente capaz de instituir mecanismos de legitimação aos sistemas de ordenamento e o uso corporativo do território. Poderíamos responder de chofre esta questão com frases, que urgentemente devem ser resgatadas:

1. Eles não sabem o que fazem, mas o fazem, famosa frase de Karl Marx usada para traçar os contornos do desconhecimento ideológico e da alienação. "Alienação que indicaria, entre outros, a incapacidade de compreensão da totalidade das estruturas causais historicamente determinadas que suportam a reprodução das relações sociais em todas as suas esferas de valores" (SAFATLE, 2008, p.83).

\section{Eles sabem o que fazem e continuam a fazê-} lo, frase de Peter Sloterdijk que afirma ser o "cinismo algo como uma ideologia reflexiva ou, ainda, uma falsa consciência esclarecida. Posições resultantes de um tempo que conhece muito bem os pressupostos ideológicos da ação, mas não encontra razão para orientar, a partir daí, a conduta" (SAFATLE, 2008, p. 71).

Em nossas pesquisas sobre o uso corporativo da esfera técnica do território brasileiro, o que temos buscado por em debate exatamente é que o processo de globalização não pode ser analisado somente como um fenômeno material (tecnológico/produtivo), ou seja, não basta analisarmos o processo de modernização do país via a expansão e adensamento dos sistemas de objetos técnico-científico informacionais que se instalam no território - ainda que tal dimensão material do território se constitua em fonte de poder sobre as quais os países avançados detêm quase o monopólio, já que detêm o controle sobre o capital de investimento, tecnologia produtiva e acesso aos mercados. Indissociavelmente a esses sistemas de objetos, um conjunto de sistemas de ações usa o território da nação, no mais das vezes como recurso econômico e fonte de poder político (KAHIL, 2008).

Ademais, nossas pesquisas nos têm demonstrado que o atual período de globalização se firma em quatro instituições supranacionais: um sistema de poder dissimuladamente centralizado pelos EUA, um sistema financeiro internacionalmente desregulado e de fluxo errático, uma produção técnico-científica informacional de alto custo como forma principal da acumulação de capital e um mercado cinicamente livre. Assim, instituições fundamentais como território, cidadãos e Estados nacionais perdem poder de articulação política (legitimidade) frente aos mecanismos de institucionalização do processo atual de globalização econômica e política.

Esse processo de institucionalização, nos dizem Peter Berger e Thomas Luckmann,

... ocorre sempre que há uma tipificação recíproca de ações habituais por tipos de atores. (...) As instituições implicam, a lém disso, a historicidade e o controle. (...) As instituições têm sempre uma história, da qual são produtos. (...) e, pelo simples fato de existirem, controlam a conduta humana, estabelecendo padrões previamente estabelecidos que a canalizam em uma direção por oposição às muitas outras direções possíveis. (...) Dizer que um segmento da atividade humana foi institucionalizado já é dizer que este segmento da atividade foi submetido ao controle social (1985, p. 79 e 80).

No Brasil, quando mal retomávamos o debate político longamente interrompido pela ditadura militar, reconhecida a dependência pela incapacidade endógena de progresso tecnológico e pela ausência de moeda conversível, segue-se a experiência brasileira de associação econômica e política do empresariado 
nacional com o capital internacional - agora renovado pela terceira revolução tecnológica e pela globalização financeira.

Então, para além da intervenção macroeconômica que levou à internacionalização do território da nação garantido pela associação econômica do empresariado nacional às empresas multinacionais (que passaram a assumir a liderança em quase todos os setores de ponta), uma intervenção política garantida pela conjugação das forças de direita e centro-direita, apaziguariam pressões populares diante do tempo longo necessário à implementação do plano econômico. Gestão econômica e técnicas de controle social garantiriam a liberalização ou livre fluxo do capital necessário para alavancar o "bendito" crescimento econômico do país.

É bom lembrar que estamos aqui nos referindo à coalizão conservadora e de centro-direita promovida por Fernando Henrique Cardoso (PSDB) - primeiro, aderindo ao governo Collor e depois se aliando ao PFL (FRIAS FILHO, 1994). Das investigações e constatações acadêmicas sobre a coalizão de poder da burguesia industrial brasileira, Fernando Henrique Cardoso, já em 1972 em seu livro Empresário industrial e desenvolvimento econômico, conclui que ela, a burguesia industrial "havia optado pela ordem, isto é, por abdicar de uma vez por todas de tentar a hegemonia plena da sociedade, satisfazendo-se com a condição de sócio-menor do capitalismo ocidental". Essa inteligência de FHC, no entanto, serviu-lhe, no momento em que participava de governos de direita, para promover a integração definitiva do país ao projeto ultra liberal mundial - portanto, "sabia o que fazia e continuava a fazê-lo".

Esta operação, de união das esferas econômica e política, anuncia um modo de desenvolvimento do capitalismo contemporâneo que não é puramente econômico, mas marcadamente um mecanismo vertical de institucionalização de forças políticas que, no caso brasileiro se traduz como um atávico totalitarismo agora não mais fundado nas "razões de estado" mas, nas "razões do mercado".

É todo um sistema muito bem articulado de ações orientadas que se impõem de um lado pela criação de uma ideologia da competitividade e crescimento econômico sem limites, e de outro, pressupoem um forte entrosamento e robusta influência nas estruturas de poder político, quer em escala nacional, quer à escala municipal. Entre as estratégias das corporações empresariais para uso eficaz do território como recurso, a promoção de políticas territoriais de desconcentração, especializações produtivas regionais, arranjos produtivos locais, são políticas muito representativas da parcialidade dos sistemas de ações globais. Toda essa orquestração (total administração) bem sucedida entre corporações privadas e poder público resultam de um labor intelectual precedente de criação de uma tecnoesfera - novos sistemas de engenharia e de movimento (sistema rodoviário, aeroviário, portuário; sistemas de distribuição e transmição de energia, etc.) generosamente financiados pelo Estado, e da criação de uma psicoesfera, em que o novo, o moderno, a idéia de crescimento e desenvolvimento são pervertidamente realizados à força perlocucionária de enunciados que prometem competitividade, fluidez, gestão eficaz, conexão ao mundo das redes, etc.

Como dissemos, as formas e conteúdos técnico-científico informacionais do meio geográfico (sua densidade e descontinuidade no território) são eles mesmos sistemas técnicos continentes de uma racionalidade instrumental que assegura a manutenção e atualização da ordem social. O próprio território, assim instrumentalizado para uso eficaz e quase exclusivo das corporações econômicas, passa a ser um mecanismo que permite a orquestração do exercício do poder - acima de tudo "um poder de dispor: de pessoas, de extensões territoriais, de bens e conhecimento, da técnica e de estruturas administrativas" (RIBEIRO, 2007). E sendo o poder, nos diz Ana Clara Ribeiro (2007) citando Claude Raffestin (1993) o poder de dispor, o seu exercício impõe, necessariamente, o domínio de todos os meios necessários ao controle e ao usufruto de recursos, o que, em cada período histórico, depende do domínio das mais relevantes fontes de energia e informação e, ainda, da sua transformação em vetores da ordem dominante. De outro lado, mas de forma sistemática, um domínio panóptico, vigilância sem trégua sobre quaisquer ameaças perturbadoras da manutenção da ordem hegemônica, dispõe também dos meios de informação para o exercício mais perverso do poder - um poder dissimulado, cínico. 
Indissociavelmente, sistemas de objetos naturais ou artificiais e sistemas de ações são perversamente usados e dispostos a serviço da manutenção e atualização do poder econômico e político das poucas e grandes corporações e instituições mundiais. O território nacional, não obstante ser uma totalidade, território de todos, espaço banal, formação sócio-espacial (SANTOS, [1979], 2003), quando é instrumentalizado, organizado e governado por forças de fora - a estrutura prevalecente não é a da nação. São forças centrífugas que retiram do lugar, das populações locais, dos governos locais, qualquer escala o tomemos (federal, estadual ou municipal) as possibilidades de presença pública autônoma, retiram do lugar as possibilidades de invenção política, de realização do espaço público. Portanto, a possibilidade de instituir-se no país a cidadania, a política e a constituição organizada de reivindicações não é suprimida apenas pela conhecida brutalidade das forças repressivas, mas passa também pelo crivo de sua instrumentalização pelo governo (e por essa via para o mercado) que as domesticando acaba por inseri-las na própria lógica do fortalecimento governamental - uma operação técnica montada que se impõe e se legítima discursivamente como políticas sofisticadas de "responsabilidade social".

Como pensarmos a política, a república, a democracia sem espaços públicos? E, se considerarmos o território como dimensão política do espaço geográfico, qual o tamanho do território da nação? Há muito já se reconhece os efeitos antipolíticos provocados pelas tecnologias de controle social e a raridade dos momentos políticos no mundo em que vivemos. Aliás, este tema das tecnologias de controle social ocupa de maneira bastante ampla o espectro do pensamento moderno, entre eles, de cientistas políticos, juristas, psicólogos, filósofos, etc. e consideramos de nosso ponto de vista, importantes leituras para revisão e atualização do tema, autores como Hebert Marcuse (1999) e Jacques Rancière (1996).

De um lado mecanismos institucionais aparecem em programas técnicos governamentais e não governamentais como mecanismos de atenuação das carências críticas em regiões pobres e degradadas do território da nação em nome da responsabilidade do poder público ou privado e, por outro lado, aparecem como "políticas de prevenção", comandadas por um contexto de insegurança que justifica qualquer medida tomada (pelo poder público ou por instituições privadas) em nome do bem-estar e manutenção da ordem social.

O Estado obrigado a ignorar as políticas macroeconômicas, cujo impacto tem ampliado as desigualdades territoriais, lança mão dos procedimentos de administração técnica das sociabilidades violentas e carências de vários tipos que proliferam desordenadamente no território dos lugares. São programas voltados para grupos sociais (meninos de rua, desabrigados, negros, analfabetos, drogados) e não para classes sociais e que são, no mais das vezes operados por entidades privadas e ONGs, parceiros a quem parece ter sido oficialmente transferida grande parte da contenção da questão social.

Nestas condições alargam-se as qualidades centrais do poder. Para além da sua ostentação manifesta historicamente no gigantismo dos sistemas de objetos técnicos (igrejas, palácios, torres, monumentos, imensas fazendas, telões, shopping center, etc...), e das exigências da mais absoluta exatidão na administração econômica - talvez a mais perversa e totalitária manifestação (dissimulada, no entanto) do poder é a normalidade com que parece alcançar a proposta de moldar a ação do Estado na empresa privada, empurrando para a sociedade civil o cuidado e a resolução das questões sociais do país em bases técnicas e funcionais para mantê-las em limites adequados, sem grandes comoções políticas. Na base dessa operação está um fato que Francisco de Oliveira chamou de "fusão entre esfera política e economia" (OLIVEIRA; PAOLI, 1999).

Em nossa pesquisa (KAHIL, 2008), para além das políticas corporativas (mal definidas) de ajustamento e manutenção de ambientes economicamente favoráveis ao crescimento e competitividade, as entrevistas realizadas nas empresas que nos receberam mostravam claramente o funcionamento da racionalidade administrativa do novo mundo do trabalhado - uma das facetas mais esclarecedoras do atual exercício de administração técnica do trabalho ou, dito de outra forma, das tecnologias de controle social. As conversas com os assessores das empresas, que nos recebiam na ocasião do trabalho de campo, revelavam os novos 
recursos técnicos para domesticação do trabalho do trabalhador: substituindo a "antiga" brutalidade dos modos de administrar o trabalho (forma taylorista), pela construção de um consenso interno (entre trabalhadores e seus chefes) e dispositivos participativos para repor o sentido do trabalho, como cursos de capacitação técnica do trabalhador, cursos que ensinam a boa conduta e a segurança do trabalho na empresa, cursos que envolvem os trabalhadores em questões do mercado, mostrando-lhes a importância da qualidade da produção - tudo impondo a "crença" de que a garantia do emprego está intimamente ligada ao estágio de competitividade da empresa no mercado.

Assim, neste nosso novo mundo do trabalho, um novo processo civilizador do trabalho, vai se forjando uma nova figuração social ao trabalhador. Os trabalhadores se tornam "colaboradores" e, àqueles mais inventivos e sem emprego, se tiverem sorte e algum talento, lhes é prometido um futuro de "empreendedorismo". Liberdade com responsabilidade... "Certamente nada poderia ser pior", nos diz Hannah Arendt.

A sociedade que está para ser libertada dos grilhões do trabalho [pelo progresso tecnológico] é uma sociedade de trabalhadores, que requer de seus membros um funcionamento automático, como se a vida individual houvesse sido afogada no processo vital da espécie e a única decisão ativa exigida do indivíduo fosse deixar-se levar... uma sociedade que já não conhece aquelas outras atividades superiores e mais importantes em beneficio das quais valeria a pena conquistar essa liberdade (ARENDT, 1991, p. 12).

Forma determinada de dominação política, sem repressões abertas externas; aparelho de estandardização e mecanização do mundo do trabalho que transforma todos em objeto de gestão. Sistemas de ações racionais e técnicas de gestão a serviço de uma eficiência no controle do trabalho, das relações sociais de produção, incluindo as relações pessoais sistemas de ações racionais, técnicas de gestão - tudo justificando a "renúncia de liberdade sob os ditames da própria razão", razões de mercado - uma submis- são razoável, razão técnica que acaba por legitimar a própria exclusão política que ela causa. (MARCUSE, 1999, p. 82).

Se num primeiro momento o consenso econômico levou os agentes sociais para longe das instituições políticas, que o próprio consenso econômico tornava obsoletas, hoje são incontáveis os canais de gesticulação cívica, que ao invés de alargar e concretizar a cidadania de fato conduzem à sua própria dissolução, desmanchando qualquer possibilidade de politização das questões cruciais do país. Baseadas na benevolência do Estado ou das empresas, e não na instituição de direitos, os programas de políticas públicas, ou os programas de responsabilidade social e ambiental das empresas e ONGs se multiplicam, fatiando os problemas sociais do país em sub-temas manejáveis tecnicamente e que só fazem acalmar, sem resolver, os calamitosos problemas das misérias, carências e inseguranças sociais. Em nossa expedição ao Centro-oeste brasileiro (outubro/2007), nos deparamos com vários exemplos de programas de responsabilidade social. Em entrevista no grupo Maggi, maior grupo de produção de soja do mundo, os assessores se vangloriavam ao nos mostrar num filme em DVD, num poderoso supertelão, um dos programas de responsabilidade social da empresa: uma creche para 200 crianças, filhos de seus funcionários. Outro exemplo dessas políticas de benevolência empresarial é o Conjunto Habitacional "Lúcia Maggi". Entrevistando os moradores eles aproveitavam nossas câmeras, como se estas fossem de uma rede de televisão, para agradecer, pois "não fosse a bondade do seu Maggi, nós estaríamos debaixo da ponte".

Cinicamente institucionalizados como políticas públicas, os mecanismos de controle social, leiamse técnicas de controle social da miséria (programas governamentais, não governamentais ou em parcerias público-privado), buscando dar legitimidade às radicais intervenções, corporativas e estatais, apelam para gestão distributiva e compensatória, que baseadas na benevolência dos poderosos acabam por instituir uma sociedade de clientes no lugar de cidadãos.

Tais programas técnicos de submissão manipulados pelos grandes mecanismos institucionais que atualizam o poder econômico e político à disposição 
da menor minoria da sociedade, são objetos de análise de Agnes Heller em Sociología de la Vida Cotidiana (1991) e foi também tratado por Wright Mills (1969, p. 183) como "procedimentos sociais racionalmente organizados que não são necessariamente um meio para aumentar a liberdade, mas são meios de tirania e manipulação, meios de expropriar a possibilidade mesma da razão, a capacidade mesma de agir como homem livre".

Assim é que tais organizações e programas vão se institucionalizando e suprimindo os élans de rebeldia, vontade de ser outro, vão amesquinhando as personalidades e acabam por esterilizar os espaços públicos - único lugar onde é possível a invenção de uma outra política.

"Alienação original", segundo as análises de Horkheimer (1976, p.119-120) em que "a esmagadora maioria das pessoas não tem 'personalidade'. Apelos à sua dignidade interior ou às suas potencialidades latentes despertam sua descrença, e isso porque tais palavras se tornaram meras frases por intermédio das quais eles são mantidos como servis. (...) O poder é a única coisa que eles respeitam e, no entanto, buscam emular".

O poder econômico, o poder político, os sistemas técnicos modernos, o consumo (tão desejado), o território, o mundo se nos aparecem reificados, i.é, "é sentido pelo homem como facticidade estranha, um opus alienum sobre o qual não tem controle, em vez de ser sentido como opus proprium de sua mesma atividade produtora". (BERGER; LUCKMANN, 1985, p.124). Assim também certas instituições podem ser apreendidas - quando lhes outorgamos um status ontológico independente da atividade e da significação humanas.

\section{CONSIDERAÇÕES FINAIS}

Tudo isso dito, recapitulo que a intenção de tratar o espírito de nossa época, a psicoesfera, revela algo de frágil e cômico na segurança do procedimento científico pragmático que se exalta como garantia de expressão da realidade dos fatos, e exige um mínimo de negatividade no debate acadêmico se a proposta é a compreensão da diversidade de formas sociais, políticas e culturais de nosso tempo. Corremos o risco.
É possível que toda nossa pretensão aqui possa não passar de um exercício do pensamento que busca até o seu limite, a chance de encontrar o caráter contingente do novo espírito do capitalismo a partir de uma perspectiva indissociável entre tecnoesfera e psicoesfera. Da perspectiva de uma teoria crítica renovada da geografia, buscamos então, fazer convergir crítica da razão e crítica às estruturas de ilusão socialmente necessárias a manutenção da crença na promessa de liberdade e igualdade do capitalismo de mercado competitivo de hoje. É possível que tal perspectiva tenha sido responsável pelo movimento sinuoso do texto; um texto marcado pelo tom ácido do pessimismo, não só como alerta contra as evidentes injustiças do mundo, mas como visão do futuro de quem deseja a esperança ao invés de pressupô-la. Talvez o saldo das reflexões expostas possa parecer negativo também por minhas próprias limitações em expor claramente as perplexidades consagradas pelo tempo, e depois, pela impossibilidade de respondê-las objetiva e conclusivamente. De fato isto deriva da própria situação de quem, percebendo a urgência de um pensamento que diante do esgotamento dos esquemas conceituais que visam orientar a ação, deseja partilhar as perplexidades e, na articulação entre reflexão e confrontação com o campo dos acontecimentos, deseja encontrar o motor de uma elaboração conceitual passível de crítica, mas que contribua para compreensão de que um outro mundo é possível.

\section{REFERÊNCIAS}

ADORNO, T. W.; HORKHEIMER, M. Dialética do esclarecimento: fragmentos filosóficos. Rio de Janeiro: Jorge Zahar Ed., 1985 [1944].

ARENDT, H. A Condição Humana. Rio de Janeiro: Forense Universitária, 1991 [1958].

BERGER, P.; LUCKMANN, T. A Construção social da Realidade. Tratado de Sociologia do Conhecimento. Petrópolis: Vozes, 1985 [1963].

BOLTANSKI, L.; CHIAPELLO, É. Le Nouvel Esprit du Capitalisme. Paris: Éditions Gallimard, 1999. 
CARDOSO, F. H. Empresário industrial e desenvolvimento econômico. São Paulo: Difel, 1972.

FRIAS FILHO, O. "Social-democratas são os outros". Folha de São Paulo. Caderno Opinião, São Paulo, 28 jul. 1994.

HELLER, Á. Sociología de la Vida Cotidiana. Barcelona: Ediciones Península, 1991 [1970].

HORKHEIMER, M. Eclipse da Razão, Rio de Janeiro, Editorial Labor do Brasil, 1976 [1947].

KAHIL, S. P. Uso do território brasileiro: densidade e fluidez das vias de circulação e do movimento no front da agricultura moderna - região Central do Brasil. Relatório de Pesquisa, FAPESP, Rio Claro, 2008.

LACLAU, E. Política e Ideologia na Teoria Marxista. Rio de Janeiro: Paz e Terra, 1978.

"Poder e Representação". Revista Estudos Sociedade e Agricultura. Rio de Janeiro, n.7, 1996, p. 7-28.

MARCUSE, H. Algumas implicações sociais da tecnologia moderna. In: KELLNER, D. (Org.). Tecnologia, guerra e fascismo. São Paulo: Unesp, 1999. p. 73-104.

OLIVEIRA, F. de; PAOLI, M. C. (Org.). Os sentidos da democracia: políticas do dissenso e hegemonia global. Petrópolis: Vozes, 1999.

RIBEIRO, A. C. T. "A voracidade do poder: dimensões do território usado". Conferência ministrada durante o Colóquio de Pesquisa O Tamanho do Brasil: território de quem - Rio Claro (SP), 18 set. 2007 (texto inédito cedido pela autora).

RAFFESTIN, C. Por uma geografia do poder. São Paulo: Ática. 1993.

RANCIÈRE, J. O desentendimento. São Paulo: Editora 34, 1996.
SAFATLE, V. Cinismo e Falencia da Crítica, São Paulo: Boitempo, 2008.

SANTOS, M. A Totalidade do Diabo: como as formas geográficas difundem o capital e mudam as estruturas sociais. In: Economia Espacial. São Paulo: Edusp, 2003 [1977. p. 31- 43].

- Metamorfoses do Espaço Habitado. Fundamentos Teóricos e Metodológicos da Geografia. São Paulo: Hucitec, 1988a.

. Réflexions sur le rôle de la géographie dans la période technico-scientifique. Cahier de Géographie du Québec, 32 (87), dec. 1988b.

- Técnica, Espaço, Tempo. Globalização e Meio Técnico-Científico Informacional. São Paulo: Hucitec, 1994.

Postface: les nouveaux mondes de la géographie. In: Bailly, A.; Ferras, R.; Pumain, D. Encyclopédie de Géographie. 2 ed. Paris: Ed. Econômica, 1995. p. 1075-1083.

. A Natureza do Espaço. Técnica e Tempo. Razão e Emoção. São Paulo: Editora Hucitec, 1996.

WRIGHT MILLS, C. A imaginação sociológica. Rio de Janeiro: Zahar Editores, 1969 [1959].

ZIZEK, S.; DALY, G. Arriscar o Impossível. São Paulo: Martins Fontes, 2006 [2004]. 